\title{
Desenvolvimento de habilidades de lógica em estudantes do ensino médio: Uma proposta
}

\section{fundamentada na neurociência}

\author{
Development of logic skills in high school students: a propostal based on \\ neuroscience
}

\author{
Narúsci S. Bastos \\ Programa de Pós-graduação em \\ Computação \\ Universidade Federal do Rio Grande \\ (FURG) \\ S/CEP - Rio Grande - RS - Brasil. \\ naruscibastos@gmail.com
}

\author{
Diana F. Adamatti \\ Programa de Pós-graduação em \\ Computação \\ Universidade Federal do Rio \\ Grande (FURG) \\ S/CEP - Rio Grande - RS - Brasil. \\ dianaada@gmail.com
}

\author{
Fernanda A. H. de Carvalho \\ Programa Pós-Graduação Eduação \\ em Ciências: Química da Vida e \\ Saúde. \\ Universidade Federal do Rio Grande \\ (FURG) - S/CEP - Rio Grande - RS \\ - Brasil \\ fahc.furg@gmail.com
}

Resumo Este trabalho propõem um estudo sobre o desenvolvimento de habilidades de lógica em estudantes do ensino médio, fundamentado na Neurociência. O objetivo é identificar possíveis mudanças na fisiologia cerebral pré e pós treinamento de lógica computacional e caracterizar as atividades cerebrais durante a resolução dos problemas do teste de lógica. Para realizar este estudo, foi necessário a coleta de sinais cerebrais em dois momentos: antes do treinamento de lógica computacional e após o treinamento. As coletas foram realizadas enquanto os individuos resolviam um teste de lógica. A partir desses dados analisam-se as áreas com maior atividade cerebral durante a resolução de cada questão proposta, que foram coletados através de técnica não-invasiva utilizando um equipamento EEG (Eletroencefalograma), que se baseia em registros de atividades elétricas cerebrais medidas através da superfície do escalpo. Estas técnicas de eletroencefalografia tem sido as mais utilizadas para a aquisição de sinais BCI (Brain Computer Interface). Os sistemas BCI permitem a comunicação entre um indivíduo e determinados dispositivos externos, baseados em atividade neural gerada pelo cérebro sem exigir qualquer outro tipo de estímulo, como movimentos musculares. Para a análise das regiões cerebrais mais ativadas, foi realizado um estudo baseado na Neurociência, que é um conjunto de disciplinas que estudam o sistema nervoso, sua estrutura, desenvolvimento, funcionamento e, evolução $e$ também suas alterações. Os resultados obtidos neste trabalho são promissores, mesmo que ainda iniciais, visto que podem contribuir para um melhor entendimento sobre as áreas cerebrais que sofrem mudanças pós treinamento em lógica computacional.

Palavras-Chave:Lógica computacional, Sistemas BCI (Brain Computer Interface), Computação, neurociência.

\footnotetext{
Abstract This work proposes a study related to the development of logic skills in high school students, based on neuroscience. The main goal is to identify possible changes in brain physiology pre and post computational logic training and to analyse brain activity during the resolution of the
}

DOI: $10.5753 /$ RBIE.2016.24.01.53 
logic test problems. To conduct this study, we have collect brain signals in two stages: before the training in computational logic of training and after this training. All data were collected while individuals solve the logic tests. In this work, we emphasize the areas with greater brain activity during the resolution of each proposed question. These data were collected through noninvasive technique, an EEG machine, which is based on electrical brain activities measured by surface scalp. These electroencephalography techniques have been the most used for the acquisition of BCI signals (Brain Computer Interface). The BCI systems enable communication between an individual and certain external devices, based on generated neural activity in the brain, without requiring any other type of stimulus, such as muscle movements. For the analysis of the activated brain regions, a study was conducted based on neuroscience, which is a set of disciplines that study the nervous system, its structure, its development, its operation and its changes.

Keywords: Computational logic, BCI systems (Brain Computer Interface), Computation, Neuroscience 


\section{Introdução}

A neurociência estuda o funcionamento, desenvolvimento e estrutura do sistema nervoso. Comumente tratada como um ramo da biologia, vem se tornando uma ciência interdisciplinar, contribuindo com campos como medicina, educação, química, computação, entre outros.

De acordo com Gazzaniga e Heatherton [13] "O pensamento atual argumenta que a maneira pela qual o pensamento do adolescente se desenvolve depende muito do conteúdo dos problemas que os adolescentes encontram e dos contextos em que se encontram”. Daí a importância de oferecer atividades de intervenção. A tecnologia tem oferecido diversas ferramentas para que os jovens possam exercitar habilidades, como a lógica, que tem papel fundamental para a capacidade de resolver problemas encontrados no dia a dia.

Desse modo, espaços educativos podem utilizar a tecnologia como ferramenta a fim de oportunizar o desenvolvimento das capacidades cognitivas dos alunos. Nesse panorama emergem as seguintes questões: Como proporcionar o desenvolvimento de competências lógicas? As ferramentas tecnológicas podem contribuir para esse desenvolvimento?

Esses questionamentos alavancaram este trabalho, o qual teve como objetivo principal investigar possíveis contribuições do treinamento de lógica computacional para o desenvolvimento de raciocínio lógico em estudantes do ensino médio. Para tal, foi necessário identificar possíveis mudanças na fisiologia cerebral pré e pós treinamento na área de lógica, bem como, caracterizar a atividade cerebral durante a realização do teste de lógica antes e depois do treinamento. Finalmente se avalia a competência/habilidade lógica dos estudantes, identificando assim possíveis diferenças de gêneros.

Este trabalho está dividido em sete seções, a seção 2, baseado na revisão teórica a partir da interlocução entre neurociência e educação, aborda a relação entre o cérebro como órgão que propicia a aprendizagem. Nesse sentido na seção 3 é enfatizado a neurociência, destacando as principais áreas cerebrais e suas ações, bem como os sitemas BCI (Brain Computer Interface), que possibilitam melhor análise dos estudos envolvendo sinais cerebrais. A seção 4 aborda a o desempenho cognitivo e a aprendizagem de lógica. Logo a seção 5 apresenta a metodologia. Os resultados são discutidos e analisados na seção 6 . Por fim, são tecidas considerações finais sobre esta pesquisa, possibilitando reflexões sobre a inserção da aprendizagem de lógica computacional nas escolas.

\section{Cérebro e Aprendizagem}

O cérebro é a parte mais importante do sistema nervoso, pois é através dele que obtemos consciência das informações que chegam pelos órgãos dos sentidos e processamos essas informações, comparando-as com nossas vivências e expectativas, sendo capaz de modificar nossos comportamentos e aprender, à ainda os processos mentais como o pensamento, capacidade de julgamento e a atenção são resultados do seu funcionamento [16]. Estas capacidades só são possíveis porque são feitas através de circuitos nervosos, os neurônios.

Segundo Cosenza e Guerra [16], no que diz respeito a nossa espécie sabe-se que não existem dois cérebros iguais, mas pode-se afirmar que "todos temos vias motoras e sensoriais que seguem o mesmo padrão". E que estas vias "estão previstas nas informações genéticas de nossas células e são construídas enquanto nosso organismo se desenvolve dentro do útero materno".

O sistema nervoso inicia sua formação nas primeiras semanas de vida embrionária. Os autores,destacam ainda que em uma primeira fase, o evento mais importante é a continua divisão das células-tronco, formando assim novos neurônios que, em um curto prazo de tempo irão aumentar significativamente seu numero inicial reduzido, chegando a bilhões.

Ainda, é preciso salientar a afirmação feita por Cosenza e Guerra [16] que diz que "A interação com o ambiente é importante porque é ela que confirmará ou induzirá a formação de conexões nervosas e, portanto, a aprendizagem ou o aparecimento de novos comportamentos que delas decorrem." [16], pois o sistema nervoso nos primeiros anos de vida apresenta o maior índice de plasticidade, a capacidade de formação de novas sinapses é muito grande, o que é justificado pelo longo período de maturação do cérebro, que se estende até os anos de adolescência. Porém, ainda que menor quando comparado ao período de maturação, a plasticidade nervosa ocorre por toda a vida, concluindo assim que a capacidade de aprendizagem é mantida, ainda que exija um pouco mais de tempo e esforço para que ocorra.

De todo processo de desenvolvimento do sistema nervoso, um dos períodos mais importantes é o que corresponde a época da adolescência, quando há um aceleramento no processo de eliminação de sinapses, um "desbastamento sináptico", que ocorre em diferentes regiões do córtex cerebral [16]. As modificações que ocorrem na adolescência preparam o individuo para a vida adulta. $\mathrm{O}$ aumento das células corticais é progressivo durante o período da infância, mas declina na adolescência até 
atingir o padrão adulto, o que reflete na otimização do potencial de aprendizagem [6]. Nesta fase diminui a capacidade de aprendizagem de novas informações,mas a um ganho na capacidade de elaborar e utilizar o que já foi aprendido.

Conforme a neurociência cognitiva, aprendizagem e memória estão fortemente relacionadas, sendo a memória a base orgânica para que ocorra a aprendizagem. Memorizar não é o mesmo que aprender, mas para que ocorra aprendizagem, é preciso que as informações fiquem armazenadas na nossa memória. Para Izquierdo [11] “A memória é o processo pelo qual aquilo que é aprendido persiste ao longo do tempo".

De acordo com Kolband Whishaw [3], o aprendizado emerge de uma experiência, tendo como resultado uma alteração no engrama, isto é, no conjunto de memórias dos sujeitos. Desse modo, as representações mentais dessas experiências são recordadas, pois a memória envolve a habilidade de resgatar ou reconhecer experiências anteriores, caracterizando um traço de memória.

Assim, a aprendizagem, ao oportunizar a aquisição de novos conhecimentos, modifica o cérebro e a conduta do indivíduo. A memória é o processo pelo qual conservamos esses conhecimentos ao longo do tempo [7].

Em seus estudos Carvalho [6], destaca que pensar, aprender e memorizar são processos biológicos realizados no cérebro, porém distintos. $\mathrm{O}$ arquivamento seletivo a evocação de informações envolve um conjunto de processos neurobiológicos e neuropsicológicos que caracterizam a memória. A aprendizagem é decisiva para o pensamento, o qual deriva da capacidade de lidar com as informações das áreas de associação motora, sensorial e mnemônica. Já o pensamento é o referencial para a orientação do comportamento, pois seu processamento envolve o recebimento, a percepção, a compreensão, o armazenamento, a manipulação, o monitoramento e o controle essenciais para lidar com o fluxo constante de dados objetivando planejar ações.

\section{BCI e Áreas Cerebrais}

O cérebro é o principal componente do sistema nervoso, pois é através do seu funcionamento que se exercem funções mentais como concentração, pensamento, capacidade de aprendizado e controle motor. Estas capacidades são executadas através de circuitos nervosos, chamados de neurônios, que atualmente podem ser explicados pelas neurociências.

O cérebro humano é dividido em dois hemisférios, direito e esquerdo, inicialmente entendia-se que existia um hemisfério dominante e outro dominado. No entanto, este conceito tornou-se ultrapassado, e que na verdade existem dois hemisférios especializados. Sendo assim cada hemisfério é responsável por um conjunto de funções, que acabam por trabalhar em conjunto.

Para Cosenza e Guerra [16], o hemisfério esquerdo é normalmente responsável pelo processamento da linguagem, que na maioria das pessoas é muito mais competente que o hemisfério direito na sua percepção e expressão, havendo algumas exceções, como indivíduos canhotos que eventualmente podem ter as áreas da linguagem localizadas no hemisfério direito. Bem como para Lent [18] o hemisfério esquerdo é também melhor na realização mental de cálculos matemáticos, no comando da escrita e na compreensão dela através da leitura. Já o hemisfério direito é melhor na percepção de sons musicais e reconhecimento de faces.

Apesar de o hemisfério esquerdo ser melhor na realização mental de cálculos matemáticos, o hemisfério direito é melhor na detecção de relações espaciais, particularmente nas relações métricas, quantificáveis, que são úteis para nosso deslocamento. O hemisfério esquerdo participa dessa função, mas com a habilidade no reconhecimento de relações espaciais e categoriais qualitativas. Embora cada hemisfério tenha sua especialidade, eles muitas vezes se complementam, assim como o hemisfério direito é especialmente capaz de identificar categorias gerais de objetos e seres vivos, o esquerdo é que detecta as categorias especificas.

Contrapondo com a complexidade do padrão de giros do encéfalo humano, os anatomistas geralmente agrupam em grandes regiões, chamadas lobos, cujos limites nem sempre são precisos, mas transmitem uma ideia inicial de localização regional. Os lobos são cinco: quatro visíveis externamente e um posicionado no interior dos grandes sulcos do encéfalo, o sulco lateral [19]. Os quatro lobos visíveis são: o frontal que é relacionado com a fronte; o parietal que se localiza sob o osso craniano do mesmo nome; o temporal relacionado com a têmpora; e o occipital sob o osso craniano homônimo, o lobo da ínsula, que só pode ser visto no momento em que se abre o sulco lateral [13][19]. Existem muitas outras estruturas situadas no sistema nervoso central (SNC), as quais muitas vezes situam-se no seu interior, porém para este trabalho importa somente compreender as quatro grandes áreas, os quatro lobos.

Cada uma dessas regiões apresentam funções especializadas como: O lobo occipital é fundamentalmente envolvido com o sentido da visão, está dividido em múltiplas áreas visuais distintas, na qual a maior é o córtex visual primário. O parietal é parcialmente dedicado ao sentido do tato, agrupa funções de sensibilidade corporal 
e reconhecimento espacial. O lobo temporal contém o córtex auditivo primário, processa dados auditivos, aspectos elaborados da visão, a compreensão linguística e alguns aspectos da memória. Finalmente, o lobo frontal que é essencial para o planejamento de ações cognitivas, memória e movimento [13][18].

Os sistemas BCI (Brain Computer Interface) surgem como ferramentas que permitem um método de comunicação baseado em atividade neural gerada pelo cérebro, sem exigir qualquer outro tipo de estímulo, como movimentos musculares criados pelos comandos cerebrais. São sistemas que utilizam sinais elétricos, detectados no escalpo da superfície cortical ou em áreas subcorticais. Seu objetivo é criar a interação entre o usuário e o dispositivo externo, como computadores, interruptores ou próteses [20].

Hans Berger, em 1929, apresentou trabalhos sobre um dispositivo que ao passar dos anos veio a ser conhecido como eletroencefalograma (EEG) [12], que poderia gravar potenciais elétricos gerados pela atividade cerebral. A partir desta ideia, quarenta anos mais tarde, os pesquisadores foram capazes de desenvolver sistemas de controle primitivo baseado na atividade elétrica cerebral.

O laboratório de BCI da UCLA (Universidade da Califórnia, Los Angeles), dirigido por Jacques Vidal, indicou que os sinais de atividade cerebral podem ser usados para comunicar eficazmente a intenção do usuário [12].

Atualmente, os sistemas BCI desenvolvidos são ferramentas que podem auxiliar os usuários a se comunicar e realizar atividades cotidianas, ainda que apresentem um sucesso limitado e se encontrem principalmente em ambientes de pesquisa. No entanto, tem sido desenvolvido para usuários com deficiências mentais e físicas, para pessoas que não apresentam nenhum tipo de deficiência e principalmente no ramo do entretenimento, na indústria de jogos digitais.

Algumas de suas funcionalidades consistem em prover um novo canal de comunicação e ampliar a interação de humanos com o mundo exterior (como pacientes com doenças neurológicas). Auxiliar na reabilitação de funções motoras através de equipamentos como neuropróteses e ainda, favorecer a análise de dados cerebrais para auxiliar na compreensão de atividade neurológica.

\subsection{Ferramenta para Coletas de Sinais Cere- brais}

A ferramenta utilizada para a coleta de sinais cerebrais ActiChamp desenvolvida por Brain Vision LLC (http://www.brainvision.com/actichamp.html), é sistema de amplificador modular, que integra grandes componentes finais para análise eletrofisiológica como EEG, ERP,
BCI, entre outros. O Actichamp é extensível para a digitalização de até 160 canais de EEG. No entanto, usou-se para a coleta dos dados apenas um módulo de 32 canais em combinação com eletrodos actiCap, que é uma touca inserida no couro cabeludo, que possui os canais expostos no padrão 10-20 onde os 32 eletrodos são inseridos para fazer o contato com cérebro do indivíduo.

Os sinais adquiridos através dos eletrodos e sensores são amplificados, digitalizados e em seguida transferidos para um computador por entrada USB, que possibilita o armazenamento e exibição dos dados. Devido a sua alta taxa de amostragem de até $100 \mathrm{KHz}$ e banda larga, o ActiChamp impõem novos padrões para amplificadores de pesquisa neurofisiológica.

O Acticap é conectado ao amplificador ActiChamp, fazendo assim a transmissão dos dados captados pelos eletrodos. Em conjunto com o conversor de impedância, os eletrodos possuem componentes que permitem que o sistema amplificador capture as impedâncias entre os eletrodos e o couro cabeludo do usuário.

Para que se tenha uma melhor compreensão, a Figura 1 apresenta como são distribuídos ao longo do encéfalo e as áreas que cada grupo de eletrodo captura, bem como o nome de cada canal.

As posições exatas para cada eletrodo estão na interseção das linhas calculadas a partir de medições entre marcos padrão no crânio. Ainda de acordo com a Figura 1 o nome de cada eletrodo, ou seja, a letra indica a região do cérebro. Em que, FP indica o lobo pré-frontal; F, lobo frontal; T, lobo temporal; $\mathrm{C}$, sulco central; $\mathrm{P}$, lobo parietal; O, lobo occipital. Já o número ou a segunda letra identificam a localização hemisférica, $\mathrm{Z}$ é a linha zero no centro da cabeça; números pares representam o hemisfério direito; números impares representam o hemisfério esquerdo. Os números são expostos em ordem crescente com o aumento da distância do centro [2].

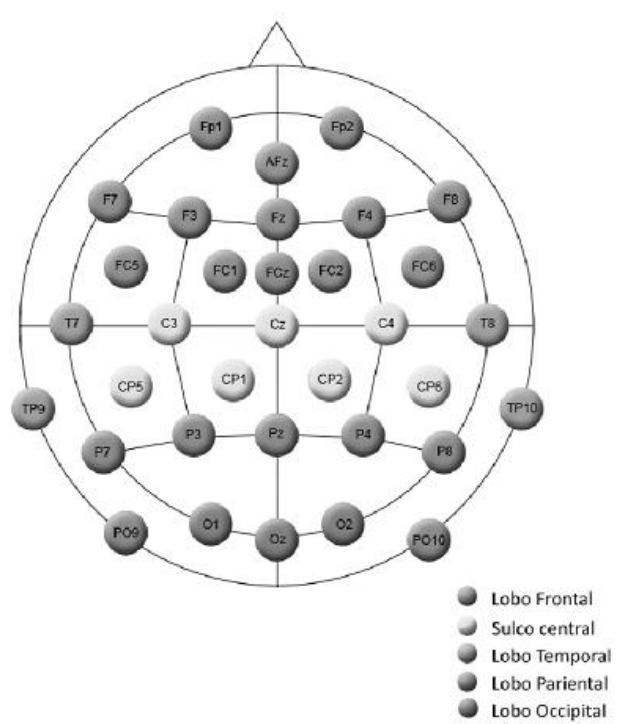


Figura 1:Localização dos eletrodos referentes aos 32 canais do Acticap (padrão internacional "10-20").

Os resultados obtidos na análise dos sinais cerebrais baseados no mapa topográfico 3D, foram validados com base na neurociência, com o auxilio de uma especialista na área. Com base na literatura de Sternberg [17] e Lent [18][19], a especialista formulou a Tabela 1 em que apresenta as regiões cerebrais, bem como os eletrodos espacialmente posicionados conforme o padrão internacional "10-20", referentes as suas funcionalidades.

\begin{tabular}{|c|c|c|}
\hline $\begin{array}{l}\text { Região } \\
\text { cerebral }\end{array}$ & Eletrodos & Função prioritária \\
\hline $\begin{array}{l}\text { Lobo fron- } \\
\text { tal }\end{array}$ & $\begin{array}{l}\text { Fp1, Fp2, } \\
\text { AFz, F7, F3, } \\
\text { Fz, F4,F8, } \\
\text { FC5, FC1, } \\
\text { FCz, FC2, } \\
\text { FC6 }\end{array}$ & $\begin{array}{l}\text { Funções executivas } \\
\text { (gerenciamento dos } \\
\text { recursos cogniti- } \\
\text { vos/emocionais } \\
\text { diante de uma dada } \\
\text { tarefa) }\end{array}$ \\
\hline $\begin{array}{l}\text { Lobo tem- } \\
\text { poral }\end{array}$ & $\begin{array}{l}\text { T7, TP9, T8, } \\
\text { T10 }\end{array}$ & $\begin{array}{l}\text { Percepção de movi- } \\
\text { mentos biológicos }\end{array}$ \\
\hline $\begin{array}{l}\text { Lobo pari- } \\
\text { etal }\end{array}$ & $\begin{array}{l}\mathrm{P} 7, \quad \mathrm{P} 3, \mathrm{Pz}, \\
\mathrm{P} 4, \mathrm{P} 8, \mathrm{P} 9, \\
\mathrm{P} 10\end{array}$ & $\begin{array}{l}\text { Percepçaõ somatos- } \\
\text { sensorial, repre- } \\
\text { sentações espaci- } \\
\text { ais e percepções } \\
\text { táteis. }\end{array}$ \\
\hline $\begin{array}{l}\text { Lobo occi- } \\
\text { pital }\end{array}$ & $\mathrm{RO} 1, \mathrm{Oz}, \mathrm{O} 2$ & $\begin{array}{l}\text { Visualização de } \\
\text { imagens (inclusive } \\
\text { durante um dialo- } \\
\text { go). }\end{array}$ \\
\hline
\end{tabular}

Tabela 1: Áreas cerebrais e suas funções proprietárias com seus eletrodos correspondentes.

\section{Capacidade Cognitiva e Aprendiza- gem Lógica}

O estudo comparativo entre jogadores e nãojogadores de videogame desenvolvido por Green e Bavelier [4] demonstra que jogar videogames propicia vantagens em diferentes aspectos da atenção visual e distribuição espacial. Não jogadores, após 10 dias de treino em vídeo games de ação tem a capacidade de atenção visual, sua resolução espacial e resolução temporal aumentadas, pois demanda detectar alvos, rastrear itens no campo visual e mudar rapidamente a ação de uma tarefa para outra.

Esse estudo, ampliado por Boot et. Al [21], ao envolver tarefas que exigiam atenção, memória e controle das funções executivas, revelou que sujeitos jogadores de videogame, rastreavam objetos mais velozmente, detec- tavam melhor as mudanças em objetos estocados na memória de curto prazo e avançavam mais rapidamente da mudança de tarefas, além de fazer a rotação mental de objetos com mais eficiência.

No que diz respeito a habilidades linguísticas e de raciocínio, estas habilidades tanto no campo da percepção espacial bem como da compreensão linguística, influenciam na aprendizagem de lógica. Com certa freqüência, a lógica é associada somente a matemática, não sendo percebida sua aplicabilidade e sua relação com as demais ciências, dentre elas a lingüística, matemática e ciências da computação. A lógica, segundo Forbellone e Eberspacher [1] pode ser vista de maneira diferente, como pode ser associada com a "correção do pensamento", pois uma de suas funções é determinar quais operações são válidas e quais não são válidas, fazendo análises das formas e leis de pensamentos. Ainda no âmbito da filosofia, ela busca respostas do porquê pensa-se de uma maneira e não de outra. Como arte ou técnica, ela ensina a usar corretamente as leis do pensamento. Observa-se ainda, que sendo o raciocínio, a forma mais complexa do pensamento, a lógica estuda a "correção do raciocínio", estuda e ensina como colocar ordem no pensamento. Tendo em vista essas ideias, nota-se a importância da lógica na vida, não só como teoria, mas como prática, uma vez que, quando um ser humano quer pensar, falar, escrever ou agir corretamente, necessita colocar "ordem no pensamento", fazendo uso da lógica.

Para Scaico et. Al [15] o aprendizado de programação é extremamente importante, pois permite o desenvolvimento de diversas capacidades que contribuem para melhorar o raciocínio lógico dos estudantes.

Sendo assim, trabalhos envolvendo o ensino de programação com a ferramenta scratch no ensino médio, como o de Scaico et. Al [15], afirma que aprender uma linguagem de programação é um desafio, no entanto, defende que o ensino de programação é importante por ter a capacidade de estimular diversas capacidades cognitivas e ainda, uma vez aprendida essas práticas podem ser utilizadas na resolução de diversos outros tipos de problemas, nas mais diversas profissões [15]. O ambiente Scratch apresenta uma linguagem que contribui para a aprendizagem de programação através de um conceito inovador orientado ao design. Motta et. Al [8] diz que o desenvolvimento de projetos na ferramenta é fácil, porque fornece um ambiente que permite a construção de projetos em forma de histórias animadas, apresentações interativas ou jogos. $\mathrm{O}$ autor afirma ainda que, o Scratch é diferente dos demais ambientes tradicionais, pois sua técnica de "arrastar e soltar" incentiva a experimentação, elimina problemas de sintaxe e permite que os alunos se 
concentrem na resolução de problemas e no design do algoritmo [8].

Scaico et. Al [15] acredita que o potencial do Scratch está além da linguagem de programação, pois é uma ferramenta capaz de provocar criatividade e o poder de exploração do programador e, principalmente de criar situações capazes de lhe explicar o funcionamento das suas estruturas de uma maneira que lhe faça sentido.

A importância de se ter uma boa habilidade de raciocínio lógico, é fundamental para o indivíduo solucionar com maior eficiência problemas do dia a dia, que normalmente são problemas mal estruturados. Existem duas classes de problemas: bem estruturados ou bem definidos e os mal estruturados ou mal definidos.

Os problemas bem estruturados possuem recursos claros, caminhos nítidos para a solução, como por exemplo uma formula matemática. Problemas mal estruturados, não apresentam recursos claros e prontamente disponíveis para a solução. As pessoas que se propõem a solucionar esses problemas apresentam dificuldades para elaborar representações mentais apropriadas para modelar esses problemas e suas resoluções. Para tais problemas, grande parte da dificuldade consiste em elaborar um plano a fim de seguir seqüencialmente uma série de passos que avancem cada vez mais próximo a solução [17][14].

Ao propor a teoria das inteligências múltiplas, divulgada no início da década de 1980, Gardner [9] destaca a inteligência lógico-matemática, que é a capacidade de realizar operações numéricas e de fazer deduções. $\mathrm{O}$ autor afirma que, esta forma de pensamento pode ser desenvolvida de um confronto com o mundo dos objetos, uma vez que é, confrontando objetos, ordenando-os, reordenando-os e avaliando sua quantidade que a criança pequena obtém seu conhecimento inicial e mais fundamental sobre a habilidade lógico-matemática. Considera ainda, que é durante o início da adolescência, ao menos nas sociedades ocidentais estudadas por piagetianos, que a criança torna-se capaz de realizar operações formais. Podendo a partir de então, não mais operar somente sobre os próprios objetos, imagens ou modelos mentais desses objetos, mas também sobre palavras, símbolos ou seqüência de símbolos que dizem respeito a objetos e ações sobre objetos. Sendo então capaz de afirmar um conjunto de hipóteses e inferir as conseqüências de cada uma [9].

Retomando a influência do meio social no desenvolvimento de habilidades cognitivas, sem dúvida, o cérebro é modificável pela cultura, pois diante da plasticidade neuronal é possível reconfigurar as redes neurais e reconstruir conhecimento. Sternberg [17] destaca que "A inteligência humana é altamente maleável. Pode ser moldada e incrementada por meio de vários tipos de inter- venções". A fase da adolescência é um momento de intenso desenvolvimento cerebral.

Para Gazzaniga e Heatherton [13] existe uma maturação contínua no córtex pré-frontal durante a idade adulta jovem, principalmente em resultado da maior mielinização, o que indica que os axônios se desenvolvem, participando de um número maior de sinapses (comunicações entre os neurônios) e, portanto, ampliando conexões neurais. Esse aumento de circuitos frontais na adolescência pode sustentar o desenvolvimento de novas capacidades cognitivas [13][ 9].

Conforme Gazzaniga e Heatherton [13] os adolescentes processam informações com mais rapidez, utilizam recursos de processamento com mais eficiência e tem maior flexibilidade cognitiva. Tal eficiência do controle cognitivo na adolescência coincide com mudanças biológicas no desenvolvimento cerebral. Os autores lembram que Piaget atribuía as mudanças no pensamento adolescente ao surgimento das operações formais.

Segundo Boyd e Bee [5], o estágio operatório-formal, propicia aos adolescentes pensar logicamente sobre ideias que não estão relacionadas a referentes concretos no mundo real. "Tipicamente esse estágio é definido como o período durante o qual os adolescentes desenvolvem esquemas operatórios que lhes permitem raciocinar logicamente sobre conceitos abstratos". Ainda conforme as autoras, todos os adolescentes e adultos neurologicamente saudáveis têm capacidade para lógica formal, mas somente aqueles cujas situações de vida exigem essa capacidade vão realmente desenvolvê-la e a experiência é um componente essencial do desenvolvimento cognitivo.

\section{Metodologia}

Este artigo teve como propósito estudar o desenvolvimento de habilidades de lógica em estudantes do ensino médio, fundamentado na Neurociência. A fim, de investigar as possíveis contribuições do treinamento de lógica computacional para o desenvolvimento de raciocínio lógico em estudantes do ensino médio, para isso foi imprescindível identificar possíveis mudanças na físiologia cerebral pré e pós treinamento de lógica computacional e caracterizar as atividades cerebrais durante a resolução dos problemas do teste de lógica. Para realizar este estudo, foi necessário a coleta de sinais cerebrais em dois momentos: antes do treinamento de lógica computacional e após o treinamento. As coletas foram realizadas enquanto os indivíduos resolviam um teste de lógica.

A partir desses dados analisou-se as áreas com maior atividade cerebral durante a resolução de cada questão proposta, que foram coletados através de técnica não- 
invasiva utilizando um equipamento EEG (Eletroencefalograma), que se baseia em registros de atividades elétricas cerebrais medidas através da superfície do escalpo. Estas técnicas de eletroencefalografia tem sido as mais utilizadas para a aquisição de sinais BCI.

Para atingirmos esses objetivos, foram realizados os seguintes passos:

1. Aplicação de questionário de perfil e teste de lógica afim de selecionar as amostras;

2. Escolha do grupo de alunos que foram analisados (alunos pertencentes aos dois últimos anos do ensino médio);

3. Execução da coleta de sinais cerebrais antes do treinamento de lógica computacional;

4. Oficina de ensino de lógica computacional, utilizando a linguagem Scratch, com duração de 24 horas/aulas, ministradas em 2 meses;

5. Coleta dos sinais cerebrais após o termino da oficina de ensino de lógica computacional;

6. Análise completa dos dados;

\section{Resultados e Discussão}

Para as coletas de sinais cerebrais, mediante autorização do CEPAS (Comitê de Ética em Pesquisa na Área da Saúde, CAAE: 34417214.3.0000.5324) tanto para a coleta pré treinamento como pós treinamento, foram aplicados, individualmente, o mesmo teste de lógica para os 3 sujeitos. Os sinais cerebrais foram coletados durante a execução de cada teste de lógica. Para isso cada sujeito teve um horário estabelecido a fim de evitar interferências, foi aplicado em local isolado dos demais, somente com a presença da pesquisadora e um assistente.

Foram formuladas duas hipóteses, uma para cada estágio da analise (pré e pós treinamento), com a intenção de verificar se as suposições são admissíveis.

As imagens foram geradas em formato 3D. No qual, representam uma média de ativação para as áreas cerebrais, sendo uma informação mais confiável.

\subsection{Coleta de Sinais Cerebrais e Analise pré treinamento}

Hipótese 1: Os alunos sem treinamento em raciocínio lógico tendem a ativar diversas áreas cerebrais. Conforme Sternberg [17], para a solução de problemas mal estruturados, como é o caso das questões de lógica, grande parte da dificuldade reside em elaborar um plano a fim de seguir seqüencialmente uma série de passos que avancem cada vez mais próximo da solução, o que favorece erros iniciais, tomada de percursos indiretos e todos os tipos de erros. Sendo assim, o conhecimento do domínio e as habilidades de justificação provaram ser importantes para a resolução de problemas. Portanto, uma vez que o indivíduo não possui boa habilidade de raciocínio lógico, possivelmente irá apresentar dificuldades ao elaborar a seqüência de passos corretos para encontrar a solução correta.

\begin{tabular}{|c|c|c|c|c|}
\hline \multicolumn{2}{|c|}{$\begin{array}{l}\text { Áreas cerebrais } \\
\text { que devem ser } \\
\text { ativadas por } \\
\text { questão }\end{array}$} & \multirow{2}{*}{$\begin{array}{c}\text { Sujeito } \\
1 \\
X\end{array}$} & \multirow{2}{*}{$\begin{array}{l}\text { Sujeito } \\
2 \\
\\
X\end{array}$} & \multirow{2}{*}{$\begin{array}{l}\underset{3}{\text { Sujeito }} \\
\\
\mathrm{X}\end{array}$} \\
\hline $\begin{array}{l}\text { Questão } \\
1\end{array}$ & $\begin{array}{l}\text { Lobo } \\
\text { frontal }\end{array}$ & & & \\
\hline & $\begin{array}{l}\text { Lobo } \\
\text { tempo- } \\
\text { ral } \\
\text { esq. }\end{array}$ & & $X$ & $X$ \\
\hline & $\begin{array}{l}\text { Lobo } \\
\text { parie- } \\
\text { tal }\end{array}$ & $X$ & $X$ & $X$ \\
\hline & $\begin{array}{l}\text { Lobo } \\
\text { occipi- } \\
\text { tal }\end{array}$ & & $X$ & $x$ \\
\hline \multirow{3}{*}{$\begin{array}{l}\text { Questão } \\
1- \\
\text { Áreas } \\
\text { não } \\
\text { neces- } \\
\text { sárias }\end{array}$} & & $\begin{array}{l}\text { Lobo } \\
\text { tempo- } \\
\text { ral } \\
\text { dir. }\end{array}$ & $\begin{array}{l}\text { Lobo } \\
\text { tempo- } \\
\text { ral } \\
\text { dir. }\end{array}$ & $\begin{array}{l}\text { Lobo } \\
\text { tempo- } \\
\text { ral } \\
\text { dir. }\end{array}$ \\
\hline & & $\begin{array}{l}\text { Sulco } \\
\text { central }\end{array}$ & $\begin{array}{l}\text { Sulco } \\
\text { central } \\
\text { dir. }\end{array}$ & $\begin{array}{l}\text { Córtex } \\
\text { pré- } \\
\text { frontal }\end{array}$ \\
\hline & & $\begin{array}{l}\text { Córtex } \\
\text { pré- } \\
\text { frontal }\end{array}$ & & \\
\hline \multirow[t]{4}{*}{$\begin{array}{l}\text { Questão } \\
2\end{array}$} & $\begin{array}{l}\text { Lobo } \\
\text { frontal } \\
\text { esq. }\end{array}$ & & & $x$ \\
\hline & $\begin{array}{l}\text { Lobo } \\
\text { tempo- } \\
\text { ral } \\
\text { dir. }\end{array}$ & $X$ & $X$ & \\
\hline & $\begin{array}{l}\text { Lobo } \\
\text { parie- } \\
\text { tal } \\
\text { dir. }\end{array}$ & $X$ & $X$ & $X$ \\
\hline & $\begin{array}{l}\text { Lobo } \\
\text { occipi- } \\
\text { tal }\end{array}$ & & $X$ & $X$ \\
\hline $\begin{array}{l}\text { Questão } \\
2-\end{array}$ & & $\begin{array}{l}\text { Lobo } \\
\text { frontal }\end{array}$ & $\begin{array}{l}\text { Lobo } \\
\text { frontal }\end{array}$ & $\begin{array}{l}\text { Lobo } \\
\text { frontal }\end{array}$ \\
\hline
\end{tabular}




\begin{tabular}{|c|c|c|c|c|}
\hline \multirow{4}{*}{$\begin{array}{l}\text { Áreas } \\
\text { não } \\
\text { neces- } \\
\text { sárias }\end{array}$} & & dir. & dir. & dir. \\
\hline & & $\begin{array}{l}\text { Córtex } \\
\text { pré- } \\
\text { frontal }\end{array}$ & $\begin{array}{l}\text { Lobo } \\
\text { tempo- } \\
\text { ral } \\
\text { esq. }\end{array}$ & $\begin{array}{l}\text { Córtex } \\
\text { pré- } \\
\text { frontal } \\
\text { dir. }\end{array}$ \\
\hline & & $\begin{array}{l}\text { Sulco } \\
\text { central } \\
\text { esq. }\end{array}$ & $\begin{array}{l}\text { Lobo } \\
\text { parie- } \\
\text { tal } \\
\text { esq. }\end{array}$ & $\begin{array}{l}\text { Lobo } \\
\text { tempo- } \\
\text { ral } \\
\text { esq. }\end{array}$ \\
\hline & & $\begin{array}{l}\text { Lobo } \\
\text { parie- } \\
\text { tal } \\
\text { esq. }\end{array}$ & $\begin{array}{l}\text { Sulco } \\
\text { central } \\
\text { dir. }\end{array}$ & \\
\hline \multirow[t]{4}{*}{$\begin{array}{l}\text { Questão } \\
3\end{array}$} & $\begin{array}{l}\text { Lobo } \\
\text { frontal } \\
\text { esq. }\end{array}$ & & & $\mathrm{x}$ \\
\hline & $\begin{array}{l}\text { Lobo } \\
\text { tempo- } \\
\text { ral }\end{array}$ & $\mathrm{x}$ & $\mathrm{x}$ & $\mathrm{x}$ \\
\hline & $\begin{array}{l}\text { Lobo } \\
\text { parie- } \\
\text { tal } \\
\text { esq. }\end{array}$ & $\mathrm{x}$ & $\mathrm{x}$ & \\
\hline & $\begin{array}{l}\text { Lobo } \\
\text { occipi- } \\
\text { tal }\end{array}$ & $\mathrm{X}$ & $\mathrm{X}$ & $\mathrm{x}$ \\
\hline \multirow{3}{*}{$\begin{array}{l}\text { Questão } \\
3 \text { - } \\
\text { Áreas } \\
\text { não } \\
\text { neces- } \\
\text { sárias }\end{array}$} & & $\begin{array}{l}\text { Sulco } \\
\text { central } \\
\text { esq. }\end{array}$ & $\begin{array}{l}\text { Lobo } \\
\text { frontal } \\
\text { dir. }\end{array}$ & $\begin{array}{l}\text { Lobo } \\
\text { frontal } \\
\text { dir. }\end{array}$ \\
\hline & & $\begin{array}{l}\text { Córtex } \\
\text { pré- } \\
\text { frontal } \\
\text { esq. }\end{array}$ & $\begin{array}{l}\text { Lobo } \\
\text { parie- } \\
\text { tal } \\
\text { dir. }\end{array}$ & $\begin{array}{l}\text { Córtex } \\
\text { pré- } \\
\text { frontal } \\
\text { dir. }\end{array}$ \\
\hline & & & $\begin{array}{l}\text { Sulco } \\
\text { central } \\
\text { dir. }\end{array}$ & $\begin{array}{l}\text { Lobo } \\
\text { parie- } \\
\text { tal } \\
\text { dir. }\end{array}$ \\
\hline \multirow[t]{4}{*}{$\begin{array}{l}\text { Questão } \\
4\end{array}$} & $\begin{array}{l}\text { Lobo } \\
\text { frontal }\end{array}$ & & $\mathrm{X}$ & $\mathrm{x}$ \\
\hline & $\begin{array}{l}\text { Lobo } \\
\text { tempo- } \\
\text { ral } \\
\text { esq. }\end{array}$ & & $\mathrm{X}$ & $\mathrm{x}$ \\
\hline & $\begin{array}{l}\text { Lobo } \\
\text { parie- } \\
\text { tal }\end{array}$ & $\mathrm{X}$ & $\mathrm{x}$ & $x$ \\
\hline & $\begin{array}{l}\text { Lobo } \\
\text { occipi- } \\
\text { tal }\end{array}$ & $\mathrm{x}$ & $\mathrm{x}$ & $x$ \\
\hline \multirow[t]{2}{*}{$\begin{array}{l}\text { Questão } \\
4- \\
\text { Áreas } \\
\text { não } \\
\text { neces- }\end{array}$} & & $\begin{array}{l}\text { Lobo } \\
\text { tempo- } \\
\text { ral } \\
\text { dir. }\end{array}$ & $\begin{array}{l}\text { Lobo } \\
\text { tempo- } \\
\text { ral } \\
\text { dir. }\end{array}$ & $\begin{array}{l}\text { Córtex } \\
\text { pré- } \\
\text { frontal } \\
\text { dir. }\end{array}$ \\
\hline & & Sulco & Sulco & \\
\hline
\end{tabular}

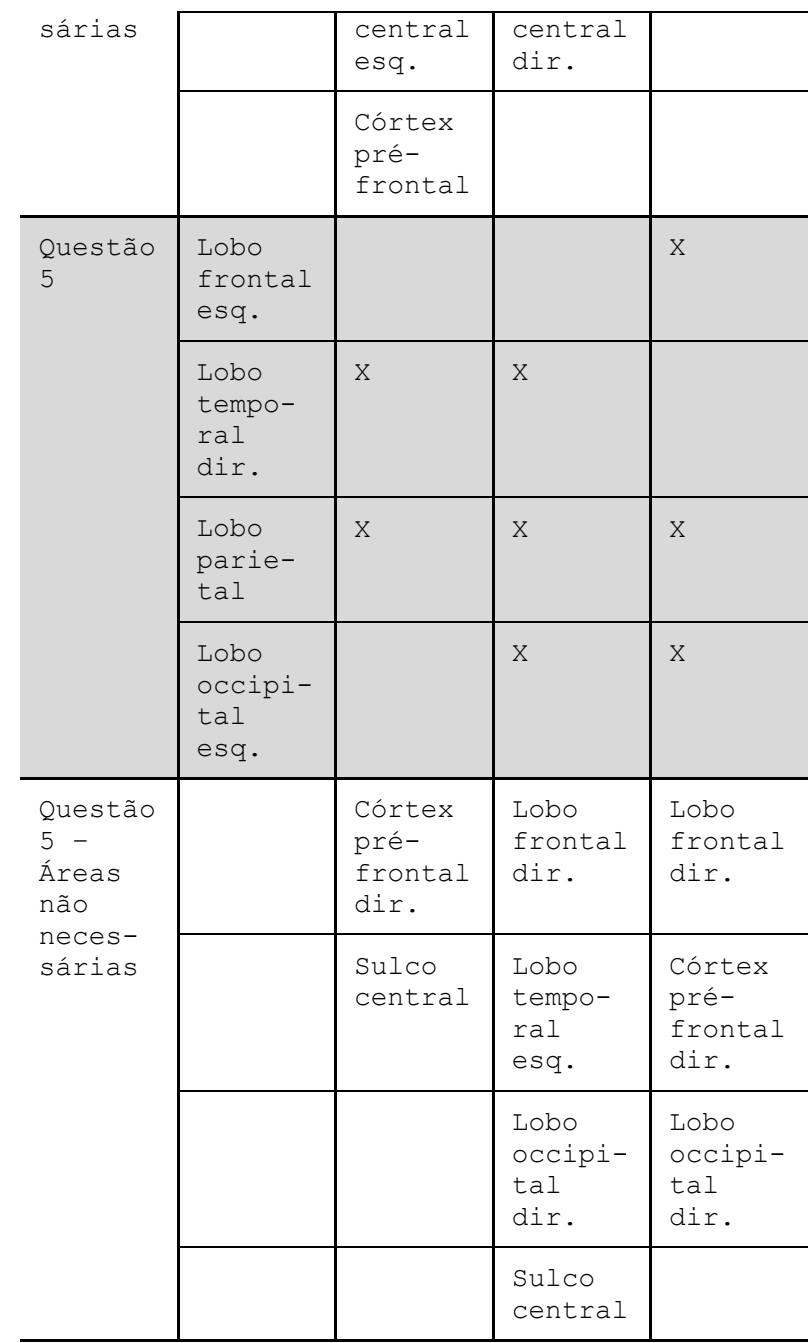

Tabela 2: Resumo das principais áreas ativadas durante a primeira coleta. As células em cinza correspondem as áreas que devem apresentar maior atividade durante a execução de cada questão. $\mathrm{O}$ "X" indica que o indivíduo ativou a área correspondente. As células brancas correspondem as áreas ativadas não esperada. As palavras "esquerdo"e "direito" indicam os hemisférios.

A Tabela 2, apresentada anteriormente, mostra as áreas que deveriam ser ativada durante a resolução de cada exercício de lógica, aplicado durante a coleta de sinais cerebrais pré treinamento para cada sujeito. Além disso, pode ser visto as áreas que tiveram mais ativação e não eram esperadas.

Conforme ainda pode ser visto na Tabela 2, as principais áreas que deveriam ser ativadas durante a execução da questão 2 , do teste de lógica aplicado antes do treinamento de lógica computacional são: o lobo frontal esquerdo, lobo temporal direito, lobo parietal direito e lobo occipital. Essas áreas são prioritárias na resolução desta questão, pois ela envolve atividade espacial e de reconhecimento de características. 
A Figura 2 mostra as atividades cerebrais executadas pelo sujeito 2 nos primeiros momentos do desenvolvimento da questão, mostra que foram ativadas diversas áreas além das esperadas, como o lobo frontal direito, temporal esquerdo, parietal esquerdo e sulco central direito.
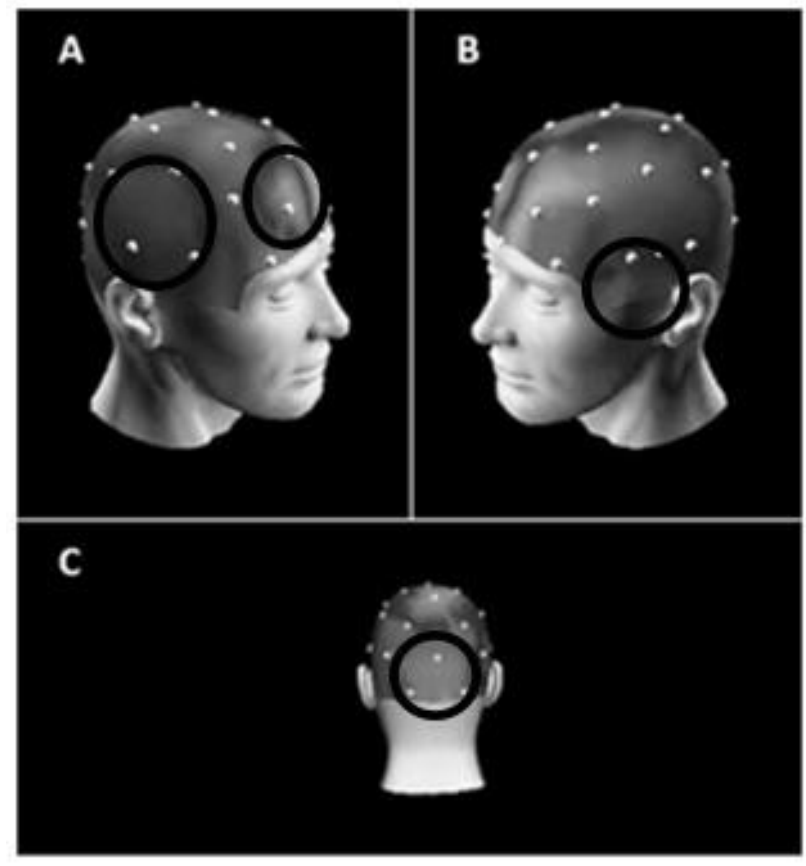

Figura 2: Principais áreas ativadas pelo sujeito 2 no início do desenvolvimento do exercício 2 durante a coleta Pré treinamento, as áreas que apresentam maior atividade estão envoltas por círculos, as marcações foram baseadas nas imagens originais, as quais são coloridas variando entre azul, vermelho, roxo, amarelo e verde, sendo a cor amarela a que apresenta maior atividade .

\subsection{Coleta de Sinais Cerebrais e Analise póstreinamento}

Hipótese 2: Os alunos com treinamento em raciocínio lógico ativam áreas cerebrais específicas. Em seus estudos, os autores Eysenck e Keane [14] observam que indivíduos tendem a ativar menos áreas cerebrais após a prática de exercícios que envolvem raciocínio. Sternberg [17], em seus achados, afirma que:

\footnotetext{
"estudos mostram que pessoas (e os melhores alunos) com muita capacidade para resolver problemas tendem a dedicar uma parte maior de seus recursos mentais ao planejamento global (o quadro mais amplo) do que as pessoas sem experiência na solução de problemas. As pessoas com pouca experiência (e os alunos fracos) tendem a alocar mais tempo ao planejamento
}

local (orientado a detalhes) em comparação às pessoas com experiência".

Sendo assim, Bloom e Broder (1950 apud [17]) afirmam que melhores alunos dedicam mais tempo na fase inicial, decidindo como solucionar um problema, e menos tempo solucionando-o efetivamente, pois ao dedicarem mais tempo decidindo antecipadamente o que fazer, os alunos eficazes apresentam menor probabilidade de ser vítimas de inícios errados, percursos indiretos e todos os tipos de erros. Com isso, indivíduos treinados, são mais propensos a tomar caminhos mais curtos e diretos para solucionar os problemas (ditos problemas mal estruturados), ativando assim um número menor de áreas cerebrais.

\begin{tabular}{|c|c|c|c|c|}
\hline \multicolumn{2}{|c|}{$\begin{array}{c}\text { Áreas cerebrais } \\
\text { que devem ser } \\
\text { ativadas por } \\
\text { questão }\end{array}$} & \multirow[t]{2}{*}{$\begin{array}{c}\text { Sujeito } \\
1\end{array}$} & \multirow{2}{*}{$\begin{array}{c}\text { Sujeito } \\
2 \\
\\
X\end{array}$} & \multirow[t]{2}{*}{$\begin{array}{c}\text { Sujeito } \\
3\end{array}$} \\
\hline $\begin{array}{l}\text { Questão } \\
1\end{array}$ & $\begin{array}{l}\text { Lobo } \\
\text { frontal } \\
\text { Dir. }\end{array}$ & & & \\
\hline & $\begin{array}{l}\text { Lobo } \\
\text { tempo- } \\
\text { ral } \\
\text { esq. }\end{array}$ & $x$ & & $X$ \\
\hline & $\begin{array}{l}\text { Lobo } \\
\text { parie- } \\
\text { tal } \\
\text { Esq. }\end{array}$ & & $x$ & $x$ \\
\hline & $\begin{array}{l}\text { Lobo } \\
\text { occipi- } \\
\text { tal }\end{array}$ & $x$ & $x$ & $X$ \\
\hline \multirow{3}{*}{$\begin{array}{l}\text { Questão } \\
1 \text { - } \\
\text { Áreas } \\
\text { não } \\
\text { neces- } \\
\text { sárias }\end{array}$} & & $\begin{array}{l}\text { Lobo } \\
\text { frontal } \\
\text { Esq. }\end{array}$ & $\begin{array}{l}\text { Lobo } \\
\text { tempo- } \\
\text { ral } \\
\text { Dir. }\end{array}$ & \\
\hline & & $\begin{array}{l}\text { Lobo } \\
\text { tempo- } \\
\text { ral } \\
\text { Dir. }\end{array}$ & $\begin{array}{l}\text { Lobo } \\
\text { parie- } \\
\text { tal } \\
\text { Dir. }\end{array}$ & \\
\hline & & $\begin{array}{l}\text { Lobo } \\
\text { parie- } \\
\text { tal } \\
\text { Dir. }\end{array}$ & & \\
\hline \multirow[t]{3}{*}{$\begin{array}{l}\text { Questão } \\
2\end{array}$} & $\begin{array}{l}\text { Lobo } \\
\text { frontal }\end{array}$ & $x$ & $X$ & \\
\hline & $\begin{array}{l}\text { Lobo } \\
\text { tempo- } \\
\text { ral } \\
\text { dir. }\end{array}$ & $x$ & $X$ & \\
\hline & $\begin{array}{l}\text { Lobo } \\
\text { parie- } \\
\text { tal }\end{array}$ & $x$ & $x$ & X \\
\hline
\end{tabular}




\begin{tabular}{|c|c|c|c|c|}
\hline & $\begin{array}{l}\text { Lobo } \\
\text { occipi- } \\
\text { tal }\end{array}$ & $\mathrm{X}$ & $x$ & $x$ \\
\hline $\begin{array}{l}\text { Questão } \\
2 \text { - } \\
\text { Áreas } \\
\text { não } \\
\text { neces- } \\
\text { sárias }\end{array}$ & & $\begin{array}{l}\text { Lobo } \\
\text { tempo- } \\
\text { ral } \\
\text { Esq. }\end{array}$ & & $\begin{array}{l}\text { Lobo } \\
\text { tempo- } \\
\text { ral } \\
\text { Esq. }\end{array}$ \\
\hline \multirow[t]{4}{*}{$\begin{array}{l}\text { Questão } \\
3\end{array}$} & $\begin{array}{l}\text { Lobo } \\
\text { frontal } \\
\text { Dir. }\end{array}$ & & $x$ & \\
\hline & $\begin{array}{l}\text { Lobo } \\
\text { tempo- } \\
\text { ral }\end{array}$ & $x$ & $x$ & $\mathrm{x}$ \\
\hline & $\begin{array}{l}\text { Lobo } \\
\text { parie- } \\
\text { tal } \\
\text { Dir. }\end{array}$ & $\mathrm{X}$ & $\mathrm{X}$ & \\
\hline & $\begin{array}{l}\text { Lobo } \\
\text { occipi- } \\
\text { tal }\end{array}$ & $x$ & $x$ & $x$ \\
\hline \multirow{2}{*}{$\begin{array}{l}\text { Questão } \\
3 \text { - } \\
\text { Áreas } \\
\text { não } \\
\text { neces- } \\
\text { sárias }\end{array}$} & & $\begin{array}{l}\text { Lobo } \\
\text { frontal } \\
\text { Esq. }\end{array}$ & $\begin{array}{l}\text { Lobo } \\
\text { frontal } \\
\text { Esq. }\end{array}$ & $\begin{array}{l}\text { Lobo } \\
\text { parie- } \\
\text { tal } \\
\text { Esq. }\end{array}$ \\
\hline & & & $\begin{array}{l}\text { Lobo } \\
\text { parie- } \\
\text { tal } \\
\text { Esq. }\end{array}$ & \\
\hline \multirow[t]{4}{*}{$\begin{array}{l}\text { Questão } \\
4\end{array}$} & $\begin{array}{l}\text { Lobo } \\
\text { frontal }\end{array}$ & $\mathrm{X}$ & $\mathrm{X}$ & \\
\hline & $\begin{array}{l}\text { Lobo } \\
\text { tempo- } \\
\text { ral } \\
\text { Dir. }\end{array}$ & $\mathrm{X}$ & $x$ & \\
\hline & $\begin{array}{l}\text { Lobo } \\
\text { parie- } \\
\text { tal }\end{array}$ & $x$ & $x$ & $x$ \\
\hline & $\begin{array}{l}\text { Lobo } \\
\text { occipi- } \\
\text { tal }\end{array}$ & $x$ & $x$ & $\mathrm{x}$ \\
\hline $\begin{array}{l}\text { Questão } \\
4 \text { - } \\
\text { Áreas } \\
\text { não } \\
\text { neces- } \\
\text { sárias }\end{array}$ & & $\begin{array}{l}\text { Lobo } \\
\text { tempo- } \\
\text { ral } \\
\text { Esq. }\end{array}$ & & $\begin{array}{l}\text { Lobo } \\
\text { tempo- } \\
\text { ral } \\
\text { Esq. }\end{array}$ \\
\hline $\begin{array}{l}\text { Questão } \\
5\end{array}$ & $\begin{array}{l}\text { Lobo } \\
\text { frontal } \\
\text { Dir. }\end{array}$ & & $x$ & $\mathrm{X}$ \\
\hline
\end{tabular}

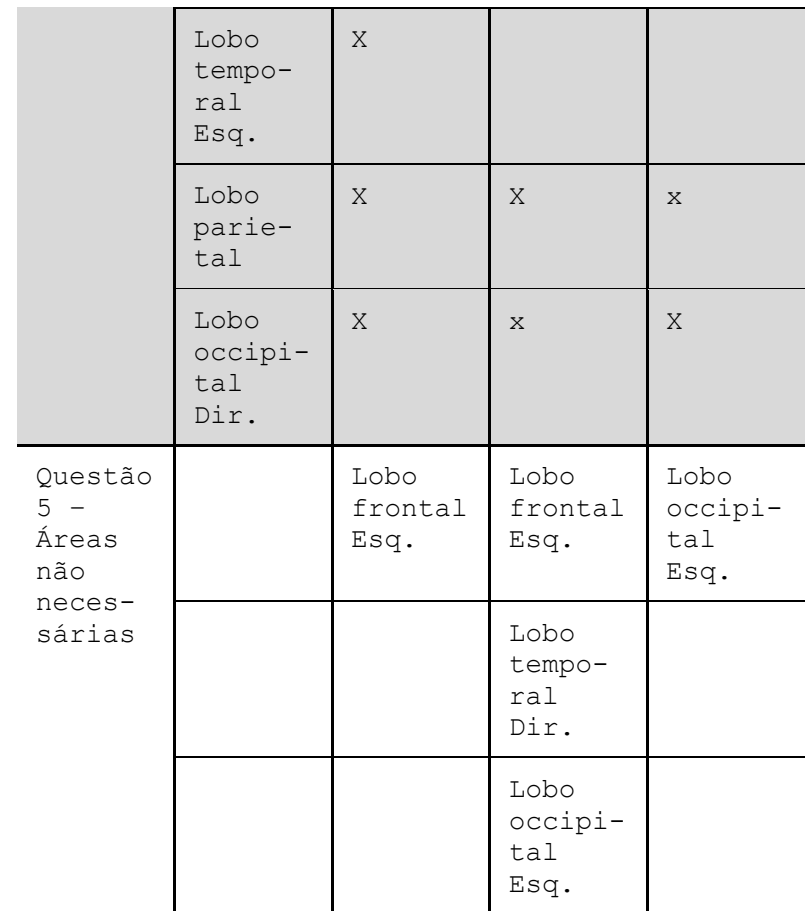

Tabela 3: Resumo das principais áreas ativadas durante a segunda coleta de dados. As células em cinza correspondem as áreas que devem apresentar maior atividade durante a execução de cada. O "X" indica que o indivíduo ativou a área correspondente. As células brancas correspondem as áreas ativadas não esperadas. As palavras "esquerdo" e "direito" indicam os hemisférios.

Conforme pode ser visto na Tabela 3 as principais áreas que deveriam ser ativadas durante o desenvolvimento da questão 2 após o treinamento de lógica computacional, que envolve a habilidade lingüística são: o lobo frontal e, lobo temporal esquerdo, lobo parietal e lobo occipital. A Figura 3 abaixo mostra as atividades cerebrais executadas pelo sujeito 2 nos primeiros momentos do desenvolvimento da questão, mostra que foram ativadas somente as áreas necessárias para a execução do exercício, pode-se observar que os lobos frontal, temporal direito, parietal e occipital mostram maior atividade.

Durante a execução da questão 2 do teste de lógica aplicado após o treinamento de lógica, nota-se que o segundo indivíduo ativou todas ás áreas necessárias para o desenvolvimento da questão, e nenhum área inesperada. 

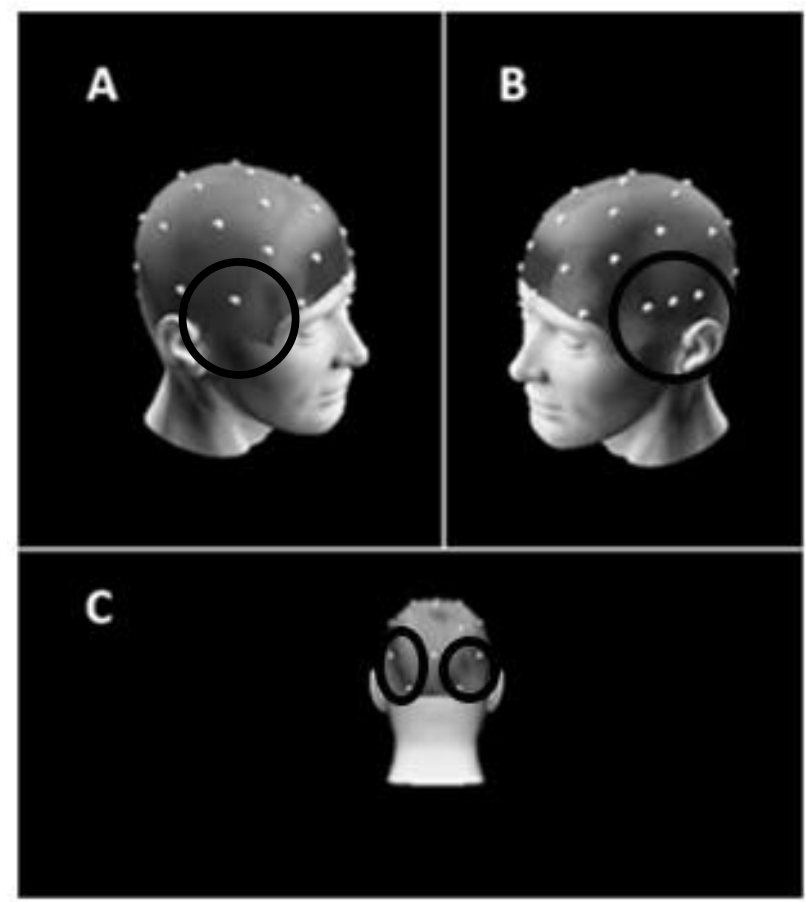

Figura 3: Principais áreas ativadas pelo sujeito 2 no início do desenvolvimento do exercício 2 durante a coleta Pós treinamento, as áreas que apresentam maior atividade estão envoltas por círculos, as marcações foram baseadas nas imagens originais, as quais são coloridas variando entre azul, vermelho, roxo, amarelo e verde, sendo a cor amarela a que apresenta maior atividade .

\section{Conclusão}

O trabalho teve como objetivo, investigar possíveis contribuições de treinamento de lógica computacional para o desenvolvimento de raciocínio lógico em estudantes do ensino médio. Para esse fim, foi necessário identificar possíveis mudanças na fisiologia cerebral pré e pós treinamento de lógica computacional, e ainda, caracterizar a atividade cerebral durante a realização de testes de lógica antes e depois do treinamento. No que diz respeito aos processos físico-químicos envolvidos na fisiologia, esses processos não foram investigados para este estudo.

Tomando como referência o objetivo do estudo, pode ser considerado que o mesmo foi atingido de modo satisfatório.

Comparando-se as hipóteses 1 e 2, observou-se alterações nas áreas do córtex cerebral que apresentavam maior ou menor atividade elétrica. Como uma primeira implicação dos resultados é possível afirmar que alunos ativaram maior número de áreas cerebrais antes de praticarem a lógica de programação.
O trabalho é inovador na área da computação a medida que são escassos os estudos no campo da lógica computacional que utilizem a captação de sinais cerebrais para analisar/acompanhar/monitorar as alterações (fisiológicas) durante o aprendizado de lógica de programação.

Ampliando o potencial dos achados, é possível também assumir que, o trabalho oferece subsidio para o desenvolvimento de outras pesquisas. Pensa-se que pode ser desenvolvido um estudo com maior tempo de treinamento, maior números de indivíduos para as coletas, e junto com o a aquisição dos sinais utilizar técnicas automáticas de mineração de dados para se encontrar resultados mais refinados, nos quais não poderem ser encontrados apenas com as imagens. Além disso, aprofundar os estudos sobre as diferenças de gênero no ensino de lógica.

\section{Referências}

[1] A. L. V. Forbellone, and H. F. Eberspacher, Lógica de Programação: A Construção de Algoritmos e Estrutura de Dados, 3th Ed. Pearson Prentice Hall, 2005.

[2] A. Vallabhaneni, T. Wang, and B. He, Braincomputer Interface, In He, B., editor, Neural Engineering, pages 85-121. Kluwer Academic, New York, 2005.

[3] B. Kolband I. Q. Whishaw, Neurociência do Comportamento, ed. Manole, São Paulo, 2002.

[4] C. S. Green and D. Bavelier, Action Video Game Modifies Visual Selective Attention, ed. Nature, 423, 534-537, 2003.

[5] D. Boyd and H. Bee, Lifespan Development, $6^{\text {th }}$ ed.Pearson, 2011.

[6] F. A. H. de Carvalho, Reaprender a Aprender: A Pesquisa como Alternativa Metacognitiva,Tese (Doutorado em Educação) Faculdade de Educação, Pontifícia Universidade Católica do Rio Grande do Sul, Porto Alegre, 2007.

[7] F. Mora, Como Funciona o Cérebro, ed. Artmed, Porto Alegre, 2004.

F. P. Mota, N. F. Ribeiro, L., Emmendorfer, P.

[ 8] Butzen, K. S. Machado., \& D. F. Adamatti. (2014). Desenvolvendo o Raciocínio Lógico no Ensino Médio: uma proposta utilizando a ferramenta Scratch. In Anais do Simpósio Brasileiro de Informática na Educação (Vol. 25, No. 1, p. 377). 
[9] H. Gardner, Frames of Mind: The Theory of Multiple Inteligence, Basic Books, 1994.

[10] H. S. Houzel, Fique de Bem com seu Cérebro: Guia Prático para o Bem-estar em 15 Passos, ed. Sextante, Rio de Janeiro, 2007.

[11] I. Izquierdo, A Arte de Esquecer, ed. Vieira e Lent, São Paulo, 2004.

[12] J. A. Silveira, Análise de Sinais Cerebrais Utilizando Árvores de Decisão . Dissertação de mestrado, Universidade Federal do Rio Grande. Pós graduação em Modelagem Computacional, 2013.

[13] M. S. Gazzaniga and T. Heatherton, Psychological Science: Mind, Brain and Behavior, ed. W.W. Norton, 2006.

[14] M. W. Eysenck, and M. T. Keane, Cognitive Phychology, Phychology Press, UK, 2005.

[15] P. D. Scaico, A. A. de Lima, J. B. B. da Silva, E. H. Raposo, Y. Alencar,...\& A. Scaico. (2013). Ensino de Programação no Ensino Médio: Uma Abordagem Orientada ao Design com a linguagem Scratch. Revista Brasileira de Informática na Educação, 21(02), 92.

[16] R. Cosenza, and L. Guerra, Neurociência e Educação, ed. Artmed, Porto Alegre, 2011.

[17] R. J. Sternberg, Cognitive Psychology, ed. Cegange Learning, 2012.

[18] R. Lent, Cem Bilhões de Neurônios: Conceitos Fundamentais de Neurociência, ed. Athenue, São Paulo, 2001.

[19] R. Lent, Neurociência da Mente e do Comportamento, ed. Athenue, Guanabara Koogan, Rio de Janeiro, 2008.

[20] S. Machado, and M. Cunha, and B. Velasques, andD. Minc, and V. Hugo, and H. B. Bastos, and M. Cagy, and R. Piedade, and P. Ribeiro,Interface Cérebro-Computador: Novas Perspectivas para a Reabilitação. Revista Neurociência, V. 17, N. 4, P. 329-335, 2009.

[21] W. R. Boot, A. F. Kramer, A. F. Simons, D. J. Fabiani, M. G. Gratton, The Effects of Video Game Playing on Attention, Memory, and Executive Control, Beckman Institute. Departament of Phychology, University of Illinois, UrbanaChampaing, Urbana, IL61801, USA. 